\title{
Proactive mechanisms for response to risks of business entities engaged in investment and construction activities
}

\author{
Anatoly Asaul ${ }^{* 10000-0002-7415-4737], \text { Maxim Asaul }}{ }^{2}$, Jury Levin ${ }^{3}$, Gennady Shcherbina ${ }^{1}$, and \\ Ekaterina Trushkovskaya ${ }^{1}$ \\ ${ }^{1}$ Saint-Petersburg State University of Architecture and Civil Engineering, 190005 Saint-Petersburg, \\ Russia \\ ${ }^{2}$ Saint-Petersburg State University of Civil Aviation, 196210 Saint-Petersburg, Russia \\ ${ }^{3}$ Moscow State Institute of International Relations, 119454 Moscow, Russia
}

\begin{abstract}
Basing on the extensive analysis of both native and foreign scientific publications, the authors have concluded that the problem of classifying risks and factors of their occurrence, and the risk assessment, as well, is well-publicized. In some works, strategies are proposed to mitigate consequences of the onset of risks by creating reserves. However, all of them are mechanisms of the management response during implementation of an investment and construction project, i.e., the reactive position. The article proposes to move from a reactive to a proactive position, which essence is to implement the goal set by the investor, regardless of the conditions, circumstances, and the likelihood of the manifestation of internal or external negative impacts. This problem is solved by the Business Impact Analysis (BIA) method, which logic is only in assessing the fact of breaching contracts by the subjects, but not the frequency of occurrence of events causing risks. The method used does not consider or observe the content of various events, their cause-and-effect relationships, but the only fact of nonfulfillment of the contract terms in relation to duration or estimated cost by a business entity implementing investment and construction projects. Keywords. Reactive position, proactive paradigm, investment and construction project, risks, proactive tools.
\end{abstract}

\section{Introduction}

The established practice of risk management, both native and foreign, in the implementation of investment and construction projects (ICPs) is based on the management response upon occurrence of a risk event (i.e., the reactive position). This is evidenced by the analysis of scientific literature on the topic under study. For instance, basing on the study of three risks - the predictors of construction costs increase: design and documentation; real estate object operation; and management risks for the construction object cost increase, the work [1] proposes consideration of social sustainability requirements at the early stages of the project

\footnotetext{
*Corresponding author: asaul@yandex.ru
} 
in order to avoid subsequent changes leading to a delay in the project and, ultimately, to the cost increase!?

The work [2] also sets sight on managing cost risks that considers characteristics of the construction cost overrun. Here the authors have developed a taxonomy of five groups of cost overrun factors related to: price, quality, design, execution, and professional skills, and are convinced that the decision-makers can understand the cost overrun behavior and effectively plan mitigation actions in the project management practices.

The results of the study [3] indicate the lack of highly qualified and skilled workers, untimely changes in design, poor performance and logistics of the facility, design inadequacy for modular development, contractual risks and disputes, lack of good cooperation and coordination, problems with approvals and interfaces, and poor consistency in construction activities as the most critical factors affecting both the cost and the schedule of ICP implementation. This study amends the baggage and helps practitioners in better understanding the key risk factors that shall be considered to create effectiveness of ICPs. In the construction industry of Cyprus, the main reasons for delays are deviations requested by the customer (70 \%), errors and missing information in the consultants' drawings (55\%), low labor efficiency (55\%), problems with financing the work by the Contractor $(52 \%)$, and inadequate work planning (50\%). Based on the results obtained, the authors [4] recommend controlling the delay of construction projects completion. Unfortunately, this is the posthumous information - a risk event has occurred. And where can we get recommendations for administrative impacts on the critical risk values? The work [5] is also just indicative of the process through which companies pass when assessing risks and how they perceive certain risks, their responses and impacts on the distribution of these risks. However, the authors are also silent how to avoid the risk, too.

The authors of the study [6] act in the same line, offering a risk management tool for implementing construction projects based on the search for effective cases originated from the study of previous projects, the use of web platforms for knowledge sharing, etc.

The authors of [7], due to their strong opinion, suggest that the main contribution of the proposed stochastic model of multicomponent resource planning is provision of a simple tool for assessing risks and uncertainties associated with limited resources, so that the necessary responsive measures can be taken to ensure success of the project. This model also provides the construction business with a simple tool for assessing ICP risks and developing a feasible and realistic project schedule. However, the exact meaning of «the necessary responsive measures to ensure the success of the project» is beyond the scope of this article.

The authors of [8] suggest that possession of knowledge and understanding of the causeand-effect relationship of the need for improvements in ICP implementation is critical for predicting their probable occurrence and developing strategies to reduce risks in the construction. As suggested, there is a need in developing a knowledge engineering system to track changes in projects so that the artificial intelligence can be used to support the uncertainty management. This, of course, is of importance, but it would be more ambitious to offer risk prevention mechanisms.

The publication [9] is of interest to us as it is based on the transaction cost economics and contributes to the increased understanding of risks and is, in many respects, consonant with the works $[10,11]$. The work [12] also has value, where 23 indicators of the investment risk from six aspects, including policy and legislation, market, financing and design, natural resources, construction, standards, and contracts are identified. This article uses a project appraisal tool to design and evaluate tasks across 23 appraisal ratios. To determine the weight of each aspect of risk, the analytical hierarchical process method is used. This study corresponds to the research of the scientific school of Methodological Problems of the Efficiency of Regional Investment and Construction Complexes as a Self-Organizing and Self-Governed System [13, 14]. 
Of particular significance for this work is the publication [15], which considers the problem of the construction target cost overrun, the sources of occurrence and risk management methods of the need for additional financing of the construction at the project definition phase. The dependence of back up funds for contingency works and costs, the cost and level of risk is found. The level of back up funds for contingency works and costs is substantiated on the basis of a process approach and a digital model of distributed risk assessment. A particular example of justifying back up funds for contingency works and costs as part of the overhaul consolidated estimate of the 1st Elagin Bridge across the Srednaya Nevka River in St. Petersburg regarding engineering design, engineering and manufacturing, price-determining, contractual and inflation risk factors is given. All of this gives evidence of the implementation of the risk assessment task, development of the effective strategy to mitigate consequences of the risk occurrence by forming back up funds for the risk situation. However, this is a management response mechanism during ICP implementation (the reactive position).

This work is purposed for creating proactive response tools to the risks of business entities carrying out ICPs.

The main goal for the study is to develop scholarly views on the response mechanism formation to the emergence of risk situations through the prism of the proactive paradigm.

\section{Methods}

In this paper, proactivity is understood as the position of the construction project customer allowing implementation of the goals set by the Investor regardless of conditions and circumstances, and the likelihood of external or internal negative impacts. The target implementation is facilitated by the Business Impact Analysis (BIA) method [16] developed on an algorithm based on the identification of critical and significant processes in relation to the goals of the business entity. With regard to ICPs, this is determination of the largest budget and the probability of threat to their components. In an ICP built on a network model, the scientific school of Methodological Problems of the Efficiency of Regional Investment and Construction Complexes as a Self-Organizing and Self-Governed System distinguishes by convention the stages with the largest budget and/or longest contracts due to high probability of its violation by executing entities [17]. Then the contract contribution to the ICP in cost and duration is assessed. Econometrically, this can be interpreted by an equation where the level of significance is assessed separately in relation to the cost and duration of the contract which express the consequences of business risks in the ICP implementation [18].

$$
W_{i}=\frac{Z_{i}}{\sum_{i=1}^{n} Z_{i}},
$$

where $W_{i}$ - is the level of significance (of cost or duration) of the $i$-th stage (of $n$ ) in the formation of project risks; and

$Z_{i}-$ is the absolute expression (of estimated cost or schedule duration) of the $i$-th stage for the results of the project.

Then the probability of the cost and schedule duration of contracts overrun from the part of business entities (the sources of risk) is estimated. For this purpose, a traditional equation is used that expresses the probability based on retrospective static observations:

$$
F_{i}=\frac{n_{i}}{m}
$$

where $F_{i}-$ is the probability of the contract cost or duration overrun at the $i$-th stage; $n_{i}-$ is the statistically observed number of breaching contracts by entities - cost or duration overrun at the $i$-th stage of the project in the real dataset; and $m$ is the population.

Take note of the difference between the logic of the equation presented and traditional approaches: only the fact of contract breaching by entities, but not the frequency of «events» that caused risks is assessed. For example, a Contractor has detected an increase in labor costs 
while implementing a contract. To put it differently, an «event» occurred, and the risk manifested. Firstly, the Contractor was able to compensate for his costs and did not pass them on to the Investor; and he fulfilled the contract within the target cost and time frames. The «event» occurred, but the risk for the Investor did not manifest. Secondly, the Contractor revised terms of the contract by cost or increased the time frame to search for new personnel. Then the risk for the Investor - a breach of the contract - manifested. Thus, the BIA method only takes into account or observes the fact of breaching the contract in terms of duration or estimated cost by the business entity implementing the ICP, but not the content of various events or their cause-and-effect relationships.

The business risk is quantitatively assessed according to two consequences - cost and duration - for the ICP. Traditionally, economic, and mathematical denomination of the business risk level in relation to the BIA method is expressed as probability times the level of significance (of cost or duration) in the formation of the ICP business risks:

$$
R_{i}=W_{i} \cdot F_{i}
$$

where $R_{i}$ is the risk level at the $i$-th stage (of $n$ ) by duration or cost. Project risks estimated by the equation to be higher than 0.25 are accepted «significant», and those above 0.5 are «critical» for the project goals [19].

Thus, the disclosed algorithm of the BIA method demonstrates its compliance with the put forward criteria: the design form of contracts arranging at ICP stages; identification and assessment of all entities subject to business risk and being in contractual relationships with the Investor, the ICP owner; the pronounced invariance, uncertainty of the algorithm to the type of events that cause the business risk; independence from the construction facility type, the versatility. The method fully complies with the proactive (preventive) approach to business risks system management of ICPs.

\section{Results and discussion}

Preliminary investigations and response mechanisms formation to emerging risks allowed setting of the following requirements to risk management tools:

1) the response entity - the Investor (in its institutional understanding, the combinatorial analysis of entities and sources of project funding);

2) response tendency to sources of business risks - Contractors in contractual relationships with the Investor.

3) differentiation of tools by ICP stages and contracts.

4) consideration of the source risk origin (entities and stages), the degree of impact of business activity on the threat formation.

5 ) the ability to compensate for selected types of risk consequences (duration and cost overruns) from the part of contractual relationship entities (with no effect on the construction Terms of Reference);

6) incorporation of the mechanism to the ICP capital planning system as costs and/or changes to the schedule plan.

The requirements put forward and analysis of the risk management mechanisms effectiveness for the ICP helped in concluding that the following three academic strategies could be used: Acceptance, Minimization, and Transfer. Since the Avoidance strategy implies a change in content or rejection of project stages that contain risk, it is not incorporated to possible approaches for investment and construction activities. The ICP project triangle (Fig. 1) only balances the dates and costs, taking as invariant the Terms of Reference for construction from the Investor side, since construction projects have no potency for rearranging the Terms of Reference. 
Invariant:

Real estate facility (land lot) parameters

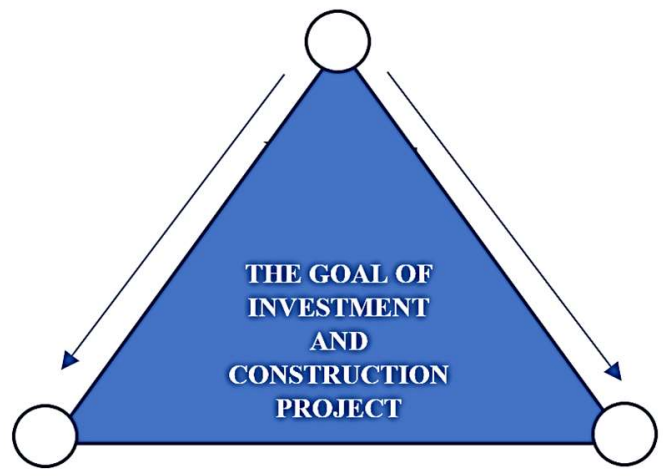

Variant: Costs

Variant: Duration

Fig. 1. Interpreting the Project Management Triangle for ICPs.

Within the selected strategies, three mechanisms for business risks management of ICPs are proposed that meet academic strategies, set forth requirements and the proactive paradigm:

1) Provisioning of funds to cover potential deficiency in the project budget (the Acceptance strategy);

2) Insurance that is the investment of funds in insurance (purchase of an insurance policy) of business risks of the project (the Minimization strategy);

3) Diversification that is distribution of liability and damage from risks by business entities implementing the ICP (the Transfer strategy).

Let us discuss the general principles and applicability of the above mechanisms for the ICP business risk management system. Table 1 shows summarized results of the possible use of mechanisms at certain stages in relation to entities of the contractual relationship.

Table 1. Possible positive mechanisms for planning responses to ICP business risks.

\begin{tabular}{|c|c|c|c|c|c|c|c|}
\hline \multirow{2}{*}{ Stage } & \multirow{2}{*}{ Contents } & \multicolumn{2}{|c|}{$R$} & \multirow{2}{*}{ Subjects } & \multicolumn{3}{|c|}{ Mechanisms } \\
\hline & & $F C$ & $T L$ & & Provisioning & Insurance & Diversification \\
\hline B & $\begin{array}{c}\text { Legal } \\
\text { arrangements... }\end{array}$ & & $\Delta \boldsymbol{\Delta}$ & Registrar of rights & + & & \\
\hline $\mathrm{C}$ & Front-End Loading... & & $\Delta \Delta$ & Technical Client & & & + \\
\hline $\mathrm{C} 1$ & Designing & & $\Delta \boldsymbol{\Delta}$ & Designer & + & & \\
\hline $\mathrm{C} 2$ & $\begin{array}{l}\text { Specification's } \\
\text { completion ... }\end{array}$ & & $\boldsymbol{\Delta}$ & $\begin{array}{l}\text { Engineering } \\
\text { Departments }\end{array}$ & + & & \\
\hline D & $\begin{array}{c}\text { Construction } \\
\text { (reconstruction)... }\end{array}$ & $\boldsymbol{\Delta}$ & $\Delta \boldsymbol{\Delta}$ & Contractor & & & + \\
\hline D1 & Construction & & $\Delta \boldsymbol{\Delta}$ & Subcontractors & & & + \\
\hline D3 & $\begin{array}{c}\text { Delivery of raw } \\
\text { materials, supplies, and }\end{array}$ & $\Delta \Delta$ & $\boldsymbol{\Delta}$ & Material Suppliers & & + & + \\
\hline E & $\begin{array}{l}\text { Registration of } \\
\text { ownership }\end{array}$ & & $\boldsymbol{\Delta}$ & Registrar of rights & + & & \\
\hline $\mathrm{F}$ & $\begin{array}{c}\text { Sales of effects of the } \\
\text { project }\end{array}$ & & $\Delta$ & Real estate agent & & + & + \\
\hline
\end{tabular}

Note. $R$ represents critical $(\boldsymbol{\Delta} \mathbf{\Delta})$ and significant $(\mathbf{\Delta})$ risks by consequences of "cost» $(F C)$ and «duration» (TL) overruns. 
The Provisioning mechanism is named so in order to distance its principles from traditional reactive sight at the risk Acceptance. To put it differently, a posteriori response to risk is opposed to a priori or proactive one. At the stage of capital planning, provisions in the scheduled duration and cost of the ICP stages are made, at which the Provisioning mechanism is to be applied, i.e., an emphasis is made on two back up resources, the cost and the duration. Basing on the reactive paradigm, the authors of [20,21] have interpreted the Risk Acceptance as acceptance of «...additional costs» [22], i.e., only in a single component of consequences - changing the cost of ICP. The consequences of business risks set forth above (para 2.1) expand the risk management field, including schedule dates as the subject of management. The project management triangle modified in relation to ICPs also allows balancing the consequences of duration and costs. This approach is a part of management response tools to business risks reserved in ICPs.

Here general principles of applying the Provisioning mechanism to planning of ICP implementation shall be set:

1) Provisioning is planning of damage in the consequences of increasing ICP costs and duration reserved in the schedule plan and the investment budget.

2) the mechanism is only accepted if no other tools can be used, for instance, insurance or diversification of risks, since it significantly reduces the level of integral ICP indices.

3 ) acceptance of potential deficiency of the ICP budget is related to the origin and sources of business risks. Meso- and macro-level external objective risks are reserved, the risks manifested via business entities implementing ICPs.

4) the Investor «accepts» risks, the potential damage of which is insignificant in total volume of the ICP, i.e., the mechanisms for planning provisions are not included (Table 2).

Table 2. Critical ( $\boldsymbol{\Delta} \boldsymbol{\Delta})$ and significant $(\boldsymbol{\Delta})$ risks $(\mathrm{R})$ at ICP stages in the cost (FC) and duration (TL) overrun zones.

\begin{tabular}{|c|c|c|c|}
\hline \multirow{2}{*}{ Stage } & \multirow{2}{*}{ Contents } & \multicolumn{2}{|c|}{$R$} \\
\hline & & $F C$ & $T L$ \\
\hline A & Formalization of investment ... & 0.001 & 0.094 \\
\hline B & Legal arrangements... & 0.027 & $0.529 \Delta \Delta$ \\
\hline C & Front-End Loading... & 0.095 & $0.539 \Delta \Delta$ \\
\hline $\mathrm{C} 1$ & Designing & 0.016 & $0.539 \Delta \Delta$ \\
\hline $\mathrm{C} 2$ & Specification's completion. & 0.001 & $0.341 \Delta$ \\
\hline $\mathrm{C} 3$ & Approval. & 0.005 & 0.142 \\
\hline D & Construction (reconstruction). & $0.323 \Delta$ & $0.601 \Delta \Delta$ \\
\hline D1 & Construction & 0.054 & $0.601 \Delta \Delta$ \\
\hline D2 & Providing machinery and equipment & 0.009 & 0.119 \\
\hline D3 & Delivery of raw materials, supplies, and ... & $0.526 \Delta \Delta$ & $0.251 \Delta$ \\
\hline $\mathrm{E}$ & Registration of ownership & 0.026 & $0.255 \Delta$ \\
\hline $\mathrm{F}$ & Sales of effects of the project & 0.019 & $0.265 \Delta$ \\
\hline
\end{tabular}

The costs of management responses and measures can be comparable to the amount of damage and it is unfeasible to use these in the planning system, accordingly.

Basing on the principles set forth, it is advisable to apply the Provisioning mechanism in relation to the stages implemented by business entities - the Registrar of Rights, Designers, and Engineering Departments. The consequence of business risks associated with these sources is the same - the increased schedule duration of the ICP. The risks of these business entities originate from objective transactional relations during approvals and examination. These are risks understood as «internal» risks of the Investor, or objective meso-level or macro-level risks that make them noninsurable or nondiversifiable. 
The proactive application of the backup tool is based on the ICP timing management. Firstly, estimated time losses at different stages (assuming those typical of ICPs according to Table 3) are included in the scheduling system of the pessimistic ICP option.

Table 3. The amount of deficiency as the average value of the overrun $(\alpha)$ of the target cost (FC) and duration (TL) at the ICP stage with regard to the standard deviation $(\sigma)$ by sample.

\begin{tabular}{|c|l|c|c|c|c|}
\hline \multirow{2}{*}{ Stage } & \multirow{2}{*}{ Contents } & \multicolumn{4}{c|}{ LS } \\
\cline { 3 - 6 } & & \multicolumn{2}{|c|}{$F C$} & \multicolumn{2}{c|}{$T L$} \\
\cline { 3 - 6 } & & $\alpha$ & $\sigma$ & $\alpha$ & $\sigma$ \\
\hline A & Formalization of investment intents & 0.005 & 0.645 & 0.120 & 0.564 \\
\hline B & Legal arrangements... & 0.117 & 0.298 & 0.780 & 0.311 \\
\hline C & Front-End Loading. & 0.275 & 0.327 & 0.799 & 0.344 \\
\hline C1 & Designing & 0.143 & 0.255 & 0.799 & 0.372 \\
\hline C2 & Specification's completion ... & 0.087 & 0.124 & 0.987 & 0.342 \\
\hline C3 & Coordination, approval and expert examination & 0.045 & 0.225 & 0.622 & 0.441 \\
\hline D & Construction ... & 0.930 & 0.224 & 0.783 & 0.346 \\
\hline D1 & Construction & 0.156 & 0.117 & 0.783 & 0.442 \\
\hline D2 & Providing machinery ... & 0.078 & 0.109 & 0.297 & 0.221 \\
\hline D3 & Supplying raw materials. & 0.696 & 0.372 & 0.370 & 0.301 \\
\hline E & Registration of ownership & 0.230 & 0.289 & 0.740 & 0.602 \\
\hline F & Sales of effects of the project ... & 0.240 & 0.119 & 0.340 & 0.377 \\
\hline
\end{tabular}

The discounted revenue is estimated with regard to changing terms and acceptability of integral indicators level of the pessimistic option for the Investor. Secondly, considering the Milestones of the project, optimization options for the relationships of stages and works are set, and indicators of the risk onset are included.

To put it differently, if an indicator shows increasing duration, the Investor shall apply an optimized option of the project schedule, built on (possible) parallelism of works and/or balancing the scheduled periods through increasing the stage cost. Of course, balancing through the stage cost is advisable when assessing economic efficiency: measures to increase the stage cost are compared with the expected loss of discounted revenue from the increased duration of the investment project. Thus, the principles, application conditions, stages, and the tool basis of the Provisioning mechanisms for proactive response to risks within the framework of the Acceptance academic strategy have been developed.

Business risk insurance is a common tool for foreign [23] and some native ICPs. In the most common - academic - interpretation, direct financial losses, or forgone revenue of the Investor as a result of risk is the subject of insurance. In foreign practice, insurance of the ICP business risks is the good practice for capital planning. Established insurance institutions offer a low rate of policy premium, however requiring fitting ICP formalization. Up to $69.4 \%$ of foreign Investors [24] in the construction industry use this mechanism for compensating direct capital losses, and $17.3 \%$ of these insure the forfeit risks. However, such contracts have a «flip side»: insurers require strict execution of the declared investment plan at all stages that reduces the flexibility of management in duration and cost of the construction project.

Unfortunately, in the native construction sector, the insurance of financial risks of Investors is a limited tool to compensate for business risks for Investors. This owes to relatively high level of risks in the investment and construction sector that makes industry rather unattractive for insurance companies. According to generalized statistical data, the share of construction companies in the industrial portfolio of insurance companies is less than $5 \%$, and the share of paid insurance premiums for «direct financial losses» and «lost revenue» of entities is less than 
$1 \%$. Firstly, the insurance of business risks is rather a supplement, a marketing technique for selling regulatory mandatory basic blocks of business (transport, medicine, etc.); and secondly, due to low institutional development of the national insurance market.

Public offers of the leading Russian insurance companies (Rosgosstrakh, Sogaz, ROSNO, Capital, etc.) studied (2019-2020) show that they are not ready to develop this line of products on a mid-term horizon. Proposals for insuring business and financial risks are focused exclusively on banks - insurance of fraud damage, whereas proposals for Investors are nominal, just providing the completeness of insurance services. At the same time, the declared level of insurance rates is «prohibitive», and its value is comparable to the objective level of ICP risks (Table 2). Insurance companies offer contracts to business entities engaged in the investment and construction activities only for construction and installation activities that are mandatory or normatively defined types of insurance.

In general, in the modern system of risk management for investment in construction projects, the Insurance mechanism has more limitations rather than opportunities. Nevertheless, analysis of insurance contracts practices allowed distinguishing two stages and types of contracts that have a case potential to be applied to investment practice in construction projects (Table 4). Firstly, the risks of losses from critical cost overrun of raw materials, materials and structures supplies can be insured. For example, you can insure the exchange risk on imports or the risk of «underdelivery» of key construction materials and structures. It makes sense to consider the potential of the Insurance tool for critical materials that significantly affect the construction project value. Secondly, it is possible to ensure marketing risks during selling the construction facility at the stage $\mathrm{F}$ of the investment project. The insurance indemnity can be focused on losses from the decreasing level of economic situation, medium- and long-term real estate market prices. It must be emphasized that these tools are secondary ones (Table 4) and are applied along with diversification mechanisms.

Table 4. Summary table of current planning mechanisms for responding to ICP risks in relation to stages and implementing entities.

\begin{tabular}{|c|c|l|}
\hline Stage & Subjects & \multicolumn{1}{|c|}{ Mechanisms } \\
\hline B, E & Registrar of rights & $\begin{array}{l}\text { Provisioning of schedule dates of the project. Composing } \\
\text { schedule alternatives, flexible parallel mechanisms for executing } \\
\text { works at stages, balancing deadlines by increasing the cost when } \\
\text { attracting additional resources }\end{array}$ \\
\hline C1 & $\begin{array}{c}\text { Designer } \\
\text { C2 }\end{array}$ & $\begin{array}{c}\text { Engineering } \\
\text { Departments }\end{array}$ \\
\hline C & Technical Client & $\begin{array}{l}\text { Diversification through contract conditions of paying the } \\
\text { management fee subject to the fulfillment of terms and estimated } \\
\text { costs of the project. The size of the management income is } \\
\text { compared with the size of the Investor's risk. The Technical Client } \\
\text { and the Contractor apply a similar diversification scheme to } \\
\text { Subcontractors to offset the risk consequences }\end{array}$ \\
\hline D1 & Subcontractors & $\begin{array}{l}\text { Diversification by transferring the risk of increasing the cost and } \\
\text { duration of the project to the entities of the contractual } \\
\text { relationship. The contracts include penalties linearly proportional } \\
\text { to the amount of potential deficiency in the cost and duration of } \\
\text { the project }\end{array}$ \\
\hline F & Material Supplies \\
\hline Real estate agent & $\begin{array}{l}\text { Diversification of risk by making contracts with incentive } \\
\text { premiums for meeting schedule deadlines. The premium is set in } \\
\text { the Investor's capital budget }\end{array}$ \\
\hline
\end{tabular}

The Diversification mechanisms - the mechanisms of risks redistribution - are considered within the Transfer academic strategy framework. The basis for formulating logics of the 
mechanism is that the Sources - Contractors who form risks within their business activity are responsible for compensation of these risks and sharing them with the Investor. In other words, the Investor's logic is based on transferring business risks to their Sources. This statement logically follows from the principles of the proactive paradigm. Contractors, being entrepreneurs, act in the same with the Investor legal and economic branch, enter business contracts, and are responsible for their breaching on the time frame and the cost of works. This mechanism is the key tool for modern practice of investment in the construction, which dominates in relations with Contractors at the ICP, stage D.

Let us set basic principles of applying the mechanism of risk compensation via redistribution or diversification (both already applied and prospective):

1) risk transfer to the Contractor at the current stage is logically justified (and can be accepted by the Contractor) if the risk originates from his business activity, independence of arranging and maintaining contractual relations with Subcontractors, and high level of the added value. For diversification, stages are distinguished accordingly, which implementation is due to independent business activity of the entity, the ICP Contractor;

2) the risk transferring tool is the 'contractual requirement' of the relevant contract conditions (and/or tender documentation for the supply or performance of work) by the Contractor;

3) the stage risk level included in the contract terms is assessed as typical and quantitatively accepted according to the data in Table 2;

4) breaching the schedule of works by the Contractor is formulated in the contract terms through the loss of the Investor profitability at the capital discount rate agreed with the Contractor (for more detail on the mechanism of interpreting duration and cost, see para. 3.2). Hence, the breaching of terms is tied to the Investor lost profit and is indemnified by the Contractor under the contract terms;

5) when using a contractual model of an Investor with integrators (of project stages), Diversification conditions or risks are transferred to the Contractor or Technical Customer. Risks are transferred (but not prescribed by the Investor) to Subcontractors by integrators on similar grounds reflected in contracts with Subcontractors;

6) the designated «hard» principles (the transfer of risk) in arranging contractual relations can be adopted in regional ICPs leveled to the perfect competition: plurality of Contractors, competitive procedures.

The above principles allow setting stages and business entities that implement ICP, to which risks can be transferred on the basis of relevant contracts. Firstly, if the relationship between the Investor and pre-design stage executors is mediated by a Technical Client, transfer of risks of increasing duration of the stage to this Technical Client is rather logical. The Technical Client is the entrepreneur and shall take on consequences of threats occurred by balancing profitability and risks. The Technical Client builds the structure of secondary contracts as the entrepreneur who understands and accepts risks of the design, approval and examination processes. Secondly, similar contractual terms of risk transfer from the Investor can be proposed as a model of Investor relationship with the Contractor. The Investor transfers risks to Contractors - suppliers of materials and construction and installation executors. However, a model of Investor - Suppliers and Work Executors direct relations is also allowed (the structure of contracts with suppliers provides for penalties for changes in the cost of raw materials and supplies) with construction and installation contractors penalties are provided for the work duration overrun. Thirdly, risk diversification is advisable at the stage of selling project results (except for facility operating by Investors to their own advantage, acting as the Customer). A real estate object (a land plot) is sold by a marketing agent, institutionally defined as a real estate agent. They most often act as market 'agents', intermediaries, i.e., taking upon themselves no business risks of the facility. Therefore, the risk transfer scheme through contractual requirements cannot be applied; only a bonus 
scheme tied to duration can be used. The contract includes a condition of additional premium to the real estate agent for fulfilling the terms of sale, which is reduced to 0 as they are exceeded. The Investor regards the premium as compensation for risk and sets it to the capital budget, which is in line with the academic logics of the Diversification mechanism.

Thus, the principles, conditions of application, stages and the tool basis of the Diversification proactive response mechanisms to risks within the framework of the Transfer academic strategy have been set out.

The description of response mechanisms to ICP business risks, an insight to the principles of their planning and implementation allow us to formulate a view of the most promising approaches in relation to the ICP institutional entities (Table 4). Approaches are considered as a practical tool for planning the budget and schedule (the Gantt chart) by the Investor, the principles and conditions for making contracts with Contractors.

Table 4 does not include the Insurance mechanism, although we do not deny its possible application (see Table 1). However, judging by the above context, the limitations have been set. As the insurance market of the regional ISCs is well-developed, the tool can be applied at D3 and F stages, taking into account the above restrictions and ICP specific features.

\section{Conclusion}

The investigation of mechanisms for compensation of business risks allowed designing proactive tools for responding to risks in relation to ICP stages and business entities implementing it. Several generalizing theoretical conclusions and provisions are formulated:

1) the possibility of using three academic strategies - Acceptance, Minimization, Transfer - is revealed. The Avoidance strategy is not included, since it implies a change in the content, rejection of ICP stages of the containing risk (not applicable in construction activities);

2) the Insurance mechanism has more restrictions rather than opportunities in the modern system of ICP risk management, due to insufficient institutional development of the insurance market.

3) mechanisms for transferring business risk (diversification) in the Investor - integrator - Contractor chain inherit the requirement of including penalties for breaching estimated (contractual) cost and/or target duration of the project.

The developed mechanisms and approaches form bases for developing a risk management monitoring system for ICP implementation aimed at increasing the competitiveness and economic efficiency of business entities in the investment and construction industry.

The authors gratefully acknowledge the team of the scientific school of Methodological Problems of the Efficiency of Regional Investment and Construction Complexes as a Self-Organizing and SelfGoverned System for help in preparing this paper.

\section{References}

1. A. Maqsoom, Z. Babar, I. Shaheen. Influence of Construction Risks on Cost Escalation of Highway-Related Projects: Exploring the Moderating Role of Social Sustainability Requirements, Iran J Sci Technol Trans Civ Eng. (2021). DOI: 10.1007/s40996-02100601-2.

2. Annamalaisami Cindrela Devi, Kuppuswamy Ananthanarayanan. Managing Cost Risks: Toward a Taxonomy of Cost Overrun Factors in Building Construction Projects, ASCEASME Journal of Risk and Uncertainty in Engineering Systems, Part A: Civil Engineering 7, Iss. 2 (2021). DOI: 10.1061/AJRUA6.0001132. 
3. Abdul Nabi Mohamad, El-adaway, Islam H. Understanding the Key Risks Affecting Cost and Schedule Performance of Modular Construction Projects, Journal of Management in Engineering 37, Iss. 4 (2021). DOI: 10.1061/(ASCE)ME.1943-5479.0000917.

4. Vacanas Yiannis, Danezis Chris. An overview of the risk of delay in Cyprus construction industry, International Journal of Construction Management 21 Iss. 4, 369-381 (2018). DOI: $10.1080 / 15623599.2018 .1541703$.

5. Panthi Kamalesh, Waller Lewis, Ahmed Syed M. Residential Construction Risk Management: Does It Happen in Real Life? Collaboration and Integration in Construction, Engineering, Management and Technology, 465-470 (2019). DOI: 10.1007/978-3-030-48465-1_77.

6. O. Okudan, C. Budayan, I. Dikmen. A knowledge-based risk management tool for construction projects using case-based reasoning, Expert Systems with Applications 173, 114776 (2021). DOI: 10.1016/j.eswa.2021.114776.

7. Isah Muritala Adebayo, Byung-Soo Kim. Integrating Schedule Risk Analysis with MultiSkilled Resource Scheduling to Improve Resource-Constrained Project Scheduling Problems, Appl. Sci. 11 (2), 650 (2021). DOI: 10.3390/app11020650.

8. Peter E.D. Love, Jane Matthews, Weili Fang. Reflections on the Risk and Uncertainty of Rework in Construction, Journal of Construction Engineering and Management 147 Iss. 4, (2021). DOI: 10.1061/(ASCE)CO.1943-7862.0002030.

9. L. Jia, Q.K. Qian, F. Meijer, H. Visscher. Exploring key risks of energy retrofit of residential buildings in China with transaction cost considerations, Journal of Cleaner Production 293, 126099 (2021). DOI: 10.1016/j.jclepro.2021.126099.

10. B. Chaparov, A. Gospodinova, I. Fedoseev, M. Yudenko. Institutional risks impact on the growth potential of construction entrepreneurship organizations, IOP Conference Series: Materials Science and Engineering 951 (1), 012030 (2020). DOI: 10.1088/1757899X/951/1/012030.

11. A.N. Asaul, S. Ivanov. Structure of transactional costs of business entities in construction, World Applied Sciences Journal, 23 (13), 80-83 (2013). DOI: 10.5829/idosi.wasj. 2013.23.pac.90017.

12. Zhai Wujuan, Ding Jiyong, Ding Leijie. Investment Risk Grade Evaluation of New Town Construction PPP Projects: Perspective from Private Sector, Journal of Urban Planning and Development 147 Iss. 2, (2021). DOI: 10.1061/(ASCE)UP.1943-5444.0000665.

13. A.N. Asaul, M. Voynarenko, L. Dzhulii, L. Skorobohata, O. Mykoliuk. The Latest Information Systems in the Enterprise Management and Trends in their Development, 9th International Conference on Advanced Computer Information Technologies, ACIT, 8779874, 409-412 (2019). DOI: 10.1109/ACITT.2019.8779874.

14. A.N. Asaul, M.P. Voynarenko, L.V. Skorobogata. Transformation of business capitalization model within the knowledge economy, Actual Problems of Economics, 161 (11), 8-15 (2014).

15. S.G. Oparin. The Problem of Exceeding the Cost of Construction and New Opportunities to Solve it at the Stage of Project Preparation, Materials Science Forum Submitted: 201804-30 931, 1122-1126 (2018). DOI: 10.4028/www.scientific.net/MSF.931.1122

16. J. Rifkin. Biosphere Politics: A New Consciousness for a New Century. N.Y.: Crown Publishing Group XI, 388 (1991).

17. A.N. Asaul, M.A. Asaul, P.B. Liulin, N.V. Chepachenko. Housing Construction in Russia: Trends and Medium-Range Forecasts, Studies on Russian Economic Development 30 (3), 313-318 (2019). DOI: 10.1134/S1075700719030055.

18. A.N. Asaul, M. Voynarenko, L. Yemchuk, L. Dzhulii. New realities of the enterprise management system information support: Economic and mathematical models and cloud technologies, Journal of Information Technology Management, 12 (3) (2020). DOI: 10.22059/JITM.2020.76293. 
19. J.C. Barnes. A Guide to Business Continuity Planning. John Wiley \& Sons, Ltd. (2001).

20. G.M. Zagidullina, A.I. Romanova, O.A. Kleshcheva, I.E. Faizullin, R.M. Ivanova. Peculiarities of housing construction development in the region, Middle East Journal of Scientific Research 16 (4), 490-495 (2013). DOI: 10.5829/idosi.mejsr.2013.16.04.11754.

21. N.A. Polovnikova, N.V. Chepachenko, M.N. Yudenko. Study and evaluation of the competitiveness potential of the organizations in the construction industry, Materials Science Forum, MSF 931, 1178-1181 (2018). DOI: 10.4028/www.scientific.net/ MSF.931.1178.

22. L. Selyutina, E. Pesotskaya, E. Rybnov, S. Sitdikov. Risk's accounting when building a management system for innovative and investment processes in construction, E3S Web of Conferences 217, 11010 (2020). DOI: 10.1051/e3sconf/202021711010.

23. N.J. Smith. Appraisal, Risk and Uncertainty (Construction Management Series). London: Thomas Telford Ltd, UK (2003).

24. N. Smith, T. Merna, P. Jobling. Managing Risk: In Construction Projects. Oxford: John Wiley \& Sons. 256 (2009). 